\title{
Commentary: Successful treatment for compensatory sweating
}

\author{
Daniel L. Miller, MD
}

\author{
From WellStar Thoracic Surgery, WellStar Health System/Mayo Clinic Care Network, Marietta, Ga. \\ Disclosures: Author has nothing to disclose with regard to commercial support. \\ Received for publication July 21, 2019; accepted for publication July 22, 2019. \\ Address for reprints: Daniel L. Miller, MD, WellStar Thoracic Surgery, WellStar Health System/Mayo Clinic \\ Care Network, 61 Whitcher St, NW, Marietta, GA 30060 (E-mail: daniel.miller@wellstar.org). \\ J Thorac Cardiovasc Surg 2019;158:1489 \\ 0022-5223/\$36.00 \\ Copyright (C) 2019 Published by Elsevier Inc. on behalf of The American Association for Thoracic Surgery \\ https://doi.org/10.1016/j.jtcvs.2019.07.064
}

Hyperhidrosis can be psychosocially unacceptable and when patients exhaust all conservative treatments they seek information about a minimally invasive sympathectomy (SX). Unfortunately, a significant number of individuals do not undergo a sympathectomy because of the fear of compensatory sweating (CS), which can be worse than the underlying disease itself. Modifications of the standard 3level SX have been performed to reduce the incidence of $\mathrm{CS}$, including single-level SX, lower-level SXs, ganglionectomy only, and reversible clamping, but no surgical variation has been $100 \%$ effective in preventing CS. ${ }^{1,2}$ Treatment of CS has been limited to topical or oral agents, clamp removable or nerve interposition of the severed sympathetic chain with less-than-acceptable results of reversing CS. Yamamoto and colleagues, ${ }^{3}$ from among the largest hyperhidrosis centers in the world, report a small series of patients treated successfully with ganglionectomy based on skin blood flow to the CS area and not temperature change to eliminate CS.

Historically, the mechanism of CS was believed to be a thermoregulatory response and untreatable. In the present study, the authors show that CS is not a physiological reaction. Eight patients with severe CS had intraoperative blood perfusion of the skin observed using laser speckle flowgraphy (LSFG), which determines the sympathetic nerves that are related to the area of skin with CS. Intraoperative monitoring using LSFG indicated the position of CS by electrical stimulation of the sympathetic ganglion and subsequent ganglionectomy was performed. In the skin area where CS was improved by ganglionectomy, a significant rise in the skin temperature was observed by postoperative thermography. Evidence that blood perfusion to the skin had increased. The authors attempted to observe the skin temperature intraoperatively; however, it was very difficult to find a significant change because of the slow speed of temperature change as well as other variables. Thus, they

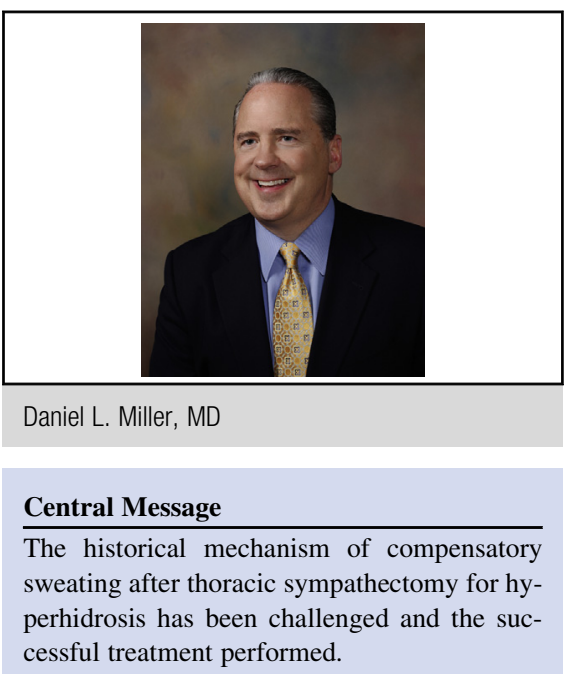

See Article page 1481 .

decided to measure the skin blood flow directly using LSFG because change in LSFG occurs within seconds after stimulating the ganglion. Interruption of the nerve circuits related to CS result in CS being ameliorated. The authors showed that CS did not increase on any other surfaces, although the area of anhidrosis was extended. Patients did not lose thermoregulatory function after the ganglionectomy because the emission of heat radiation increased from the anhidrosis area and the body temperature of the patients was constant. Therefore, CS is not a thermoregulatory response. The authors should be applauded for discovering the true mechanisms of CS, but more importantly successfully treating post-SX-debilitating CS. To confirm their hypothesis, other centers throughout the world will need to reproduce their intraoperative findings and postoperative success, which may be a daunting task that involves perfecting intraoperative LSFG. I look forward to that challenge and adventure!

\section{References}

1. Miller DL, Bryant AS, Force SD, Miller JI Jr. Effect of sympathectomy level on the incidence of compensatory hyperhidrosis after sympathectomy for palmar hyperhidrosis. J Thorac Cardiovasc Surg. 2009;138:581-5.

2. Cerfolio RJ, De Campos JR, Bryant AS, Connery CP, Miller DL, DeCamp MM et al. The Society of Thoracic Surgeons expert consensus for the surgical treatment of hyperhidrosis. Ann Thorac Surg. 2011;91:1642-8.

3. Yamamoto H, Okada M. The management of compensatory sweating after thoracic sympathectomy. J Thorac Cardiovasc Surg. 2019;158:1481-8. 